Article

\title{
Template-Free Synthesis of a Phenanthroline-Containing [2]Rotaxane: A Reversible pH-Controllable Molecular Switch
}

\author{
Masahiro Muraoka ${ }^{1, * \mathbb{C}}$, Kakeru Aoyama ${ }^{1}$, Sae Fujihara ${ }^{1}$, Risa Yamane ${ }^{1}$, Ichiro Hisaki ${ }^{2}{ }^{\mathbb{D}}$, \\ Mikiji Miyata ${ }^{3}$, Michihisa Murata ${ }^{1}{ }^{1}$ and Yohji Nakatsuji ${ }^{1}$ \\ 1 Department of Applied Chemistry, Faculty of Engineering, Osaka Institute of Technology, 5-16-1 Ohmiya, \\ Asahi-ku, Osaka 535-8585, Japan \\ 2 Research Institute for Electronic Science, Hokkaido University, N20, W10, Sapporo, \\ Hokkaido 001-0020, Japan \\ 3 Department of Material and Life Science, Graduate School of Engineering, Osaka University, 2-1 Yamadaoka, \\ Suita, Osaka 565-0871, Japan \\ * Correspondence: masahiro.muraoka@oit.ac.jp; Tel.: +81-6-6954-4268
}

Received: 20 August 2019; Accepted: 3 September 2019; Published: 6 September 2019

check for updates

\begin{abstract}
The synthesis of symmetric and asymmetric rotaxanes consisting of neutral axle and ring components without ionic templates is necessary for applications in molecular sensors and molecular switches. A phenanthroline-containing symmetric [2]rotaxane was newly synthesized by inducing hydrogen bonding and $\pi$-interaction using a template-free threading-followed-by-stoppering method. The obtained rotaxane serves as a reversible $\mathrm{pH}$-controllable molecular switch.
\end{abstract}

Keywords: rotaxane; interlocked molecule; molecular switch; acid-base response

\section{Introduction}

Rotaxanes represent one of the many kinds of mechanically interlocked molecules (MIMs) and have been thoroughly investigated in the context of molecular machines and molecular switches [1-6]. Meanwhile, rotaxanes have found interesting applications in molecular sensors and catalysts due to their specific interconversion and their intrinsic cavities, which arise from three-dimensional threaded structures [7-10]. Even so, controlled synthetic routes to rotaxanes, that is, the systematic discovery of new compatible combinations of axle and ring components, still remains challenging. At present, cationic hydrogen-bonding template and metal template have been widely used to achieve effective threading of an axle through a macrocycle, even though neutralizing the cationic moiety and removing the metal ions are necessary in the later step [11-15]. Therefore, studies focused on different types of threading of neutral axle components without template ions through macrocycles are required in order to synthesize interlocked molecules that may find applications in molecular sensors [16-21]. In the molecular design of rotaxanes, we discovered new host-guest pairs. Herein, we report the synthesis of a new symmetric rotaxane 3 that uses an isophthalamide derivative 1 with a half dibenzo-crown ether as a ditopic ring component in combination with a phenanthroline derivative $\mathbf{2}$ as an axle. Moreover, we demonstrate that these MIMs can serve as reversible $\mathrm{pH}$-controlled molecular switches between two stations on the phenanthroline and the protonated aniline site (Scheme 1). 

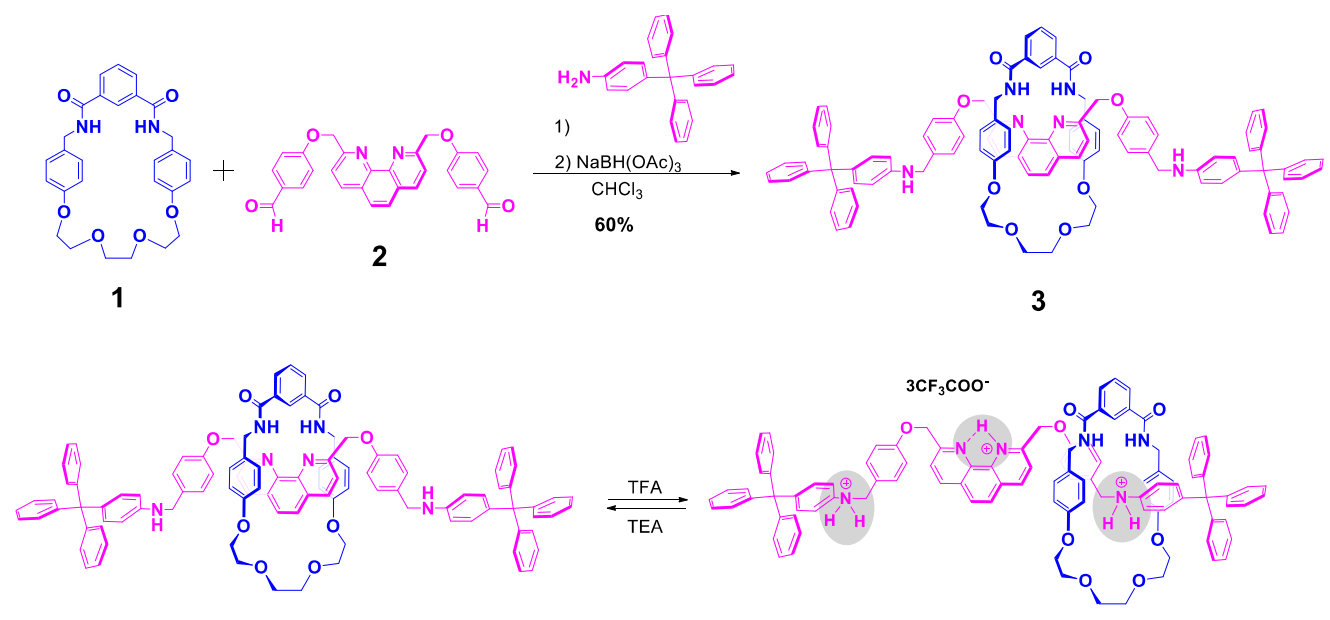

3

Scheme 1. Formation of rotaxane 3 using an end-capping method and an acid-base molecular switching of 3. TFA, trifluoroacetic acid; TEA, triethylamine.

\section{Materials and Methods}

All reagents were obtained from commercial suppliers (tritylaniline; Alfa Aesar by Thermo Fisher Scientific, Heysham, Lancasshire, U.K., sodium triacetoxyborohydride; Tokyo Chemical Industry Co., Ltd., Tokyo, Japan, other reagents and solvents; FUJIFILM Wako Pure Chemical Co., Osaka, Japan) and used as received. Macrocycle 1 [22] and thread precursor 2 [23] were synthesized according to literature procedures. ${ }^{1} \mathrm{H}$ and ${ }^{13} \mathrm{C}$ NMR spectra were recorded with a Varian Mercury 300 spectrometer (Agilent Technologies Japan, Ltd., Tokyo, Japan) for solution in $\mathrm{CDCl}_{3}$ with $\mathrm{SiMe}_{4}$ as an internal standard. Mass spectra were measured on a Shimadzu LCMS-IT-TOF mass spectrometer (Shimadzu Co., Kyoto, Japan) using the electrospray ionization (ESI) method. Preparative gel permeation chromatography (GPC) was performed with JAI LC-908 (Japan Analytical Industry Co. Ltd., Tokyo, Japan) on JAIGEL 1H and $2 \mathrm{H}$ columns with $\mathrm{CHCl}_{3}$ as a solvent. ${ }^{1} \mathrm{H}$ NMR and ${ }^{13} \mathrm{C}$ NMR spectra of [2]rotaxane 3 and dumbbell 4 as well as ROESY NMR spectra of [2]rotaxane 3 are shown in Appendices A-D.

\subsection{Synthesis of Rotaxane 3}

A solution of macrocycle $1(50.0 \mathrm{mg}, 0.102 \mathrm{mmol})$, thread precursor $2(46.0 \mathrm{mg}, 0.103 \mathrm{mmol})$, and tritylaniline $(73.0 \mathrm{mg}, 0.218 \mathrm{mmol})$ in chloroform $(4 \mathrm{~mL})$ containing $\mathrm{MgSO}_{4}$ as a dehydrating agent was stirred for $96 \mathrm{~h}$ at room temperature under Ar. Sodium triacetoxyborohydride (109 mg, $5.55 \mathrm{mmol}$ ) was added and the mixture was stirred for a further $48 \mathrm{~h}$. The reaction mixture was washed with water $(3 \times 10 \mathrm{~mL})$, and the solvent was removed under reduced pressure to yield the crude mixture, which was purified by preparative GPC to yield [2]rotaxane $3(96.3 \mathrm{mg}, 60 \%)$ and corresponding free dumbbell $4(24.1 \mathrm{mg}, 15 \%)$ as a clear yellow solid. [2]Rotaxane 3: ${ }^{1} \mathrm{H} \mathrm{NMR}\left(300 \mathrm{MHz}, \mathrm{CDCl}_{3}\right) \delta 10.28$ $(\mathrm{s}, 1 \mathrm{H}), 8.36(\mathrm{~d}, 2 \mathrm{H}, J=8.4 \mathrm{~Hz}), 8.32(\mathrm{~d}, 2 \mathrm{H}, J=8.1 \mathrm{~Hz}), 8.04(\mathrm{t}, 2 \mathrm{H}, J=3.9 \mathrm{~Hz}), 7.95(\mathrm{~s}, 2 \mathrm{H}), 7.71(\mathrm{~d}, 2 \mathrm{H}$, $J=8.4 \mathrm{~Hz}), 7.60(\mathrm{t}, 1 \mathrm{H}, J=7.8 \mathrm{~Hz}), 7.24-7.12(\mathrm{~m}, 36 \mathrm{H}), 6.97(\mathrm{~d}, 4 \mathrm{H}, J=8.7 \mathrm{~Hz}), 6.67(\mathrm{~d}, 4 \mathrm{H}, J=8.7 \mathrm{~Hz})$, $6.54(\mathrm{~d}, 4 \mathrm{H}, J=8.7 \mathrm{~Hz}), 5.89(\mathrm{~d}, 4 \mathrm{H}, J=8.4 \mathrm{~Hz}), 5.61(\mathrm{~d}, 4 \mathrm{H}, J=8.4 \mathrm{~Hz}), 4.86(\mathrm{~s}, 4 \mathrm{H}), 4.19(\mathrm{~s}, 4 \mathrm{H}), 4.00$ $(\mathrm{s}, 4 \mathrm{H}), 3.98(\mathrm{~s}, 4 \mathrm{H}), 3.90(\mathrm{~d}, 4 \mathrm{H}, J=5.1 \mathrm{~Hz}), 3.83(\mathrm{~d}, 4 \mathrm{H}, J=4.5 \mathrm{~Hz}) \mathrm{ppm} ;{ }^{13} \mathrm{C} \mathrm{NMR}\left(75 \mathrm{MHz}, \mathrm{CDCl}_{3}\right): \delta$ 165.8, 158.0, 157.4, 157.3, 147.4, 146.0, 144.5, 137.1, 133.6, 132.4, 132.2, 132.1, 131.3, 129.3, 128.5, 128.2, 128.1, 127.5, 127.4, 126.5, 126.2, 125.8, 121.1, 114.9, 114.3, 113.3, 112.0, 69.8, 65.2, 64.3, 43.7, 29.1, 28.6, 25.7 ppm; HR-MS(ESI) $m / z$ calc. for $\left[\mathrm{C}_{106} \mathrm{H}_{92} \mathrm{~N}_{6} \mathrm{O}_{8}+\mathrm{Na}^{+}\right]$: 1599.6874; found: 1599.6796. Dumbbell 4: ${ }^{1} \mathrm{H}$ NMR $\left(300 \mathrm{MHz}, \mathrm{CDCl}_{3}\right): \delta 8.31(\mathrm{~d}, 2 \mathrm{H}, J=8.1 \mathrm{~Hz}), 7.95(\mathrm{~d}, 2 \mathrm{H}, J=8.4 \mathrm{~Hz}), 7.82(\mathrm{~s}, 2 \mathrm{H}), 7.31$ $(\mathrm{d}, 4 \mathrm{H}, J=8.7 \mathrm{~Hz}), 7.23-7.13(\mathrm{~m}, 32 \mathrm{H}), 7.04(\mathrm{~d}, 4 \mathrm{H}, J=9.0 \mathrm{~Hz}), 6.98(\mathrm{~d}, 4 \mathrm{H}, J=8.7 \mathrm{~Hz}), 6.53(\mathrm{~d}, 4 \mathrm{H}$, $J=8.7 \mathrm{~Hz}), 5.64(\mathrm{~s}, 4 \mathrm{H}), 4.22(\mathrm{~s}, 4 \mathrm{H}) \mathrm{ppm} ;{ }^{13} \mathrm{C} \mathrm{NMR}\left(75 \mathrm{MHz}, \mathrm{CDCl}_{3}\right): \delta 158.5,157.9,147.4,146.0,145.3$, $137.3,136.1,132.2,132.0,131.3,129.3,128.4,127.4,126.5,125.8,121.0,115.1,112.0,71.6,64.3,48.2$ ppm. 


\subsection{Single Crystal X-Ray Analysis}

X-ray diffraction data were collected on a Rigaku R-AXIS RAPID diffractometer (Rigaku Co., Tokyo, Japan) with a 2-D area detector using graphite-monochromatized $\mathrm{CuK} \alpha$ radiation $(\lambda=1.54187 \AA)$. SHELXT (ver. May 2014, Sheldrick, G. M. (2014). Acta Cryst. A70, C1437.) [24] was used for the structure solution of the crystals. All calculations were performed with the observed reflections $[I>2 \sigma(I)]$ by the program CrystalStructure crystallographic software packages (ver. 4.2.4, Rigaku Corporation (2000-2016), Tokyo, Japan) [25] except for refinement, which was performed using SHELXL (ver. July 2014, Sheldrick, G. M. (2008). Acta Cryst. A64, 112-122.) [26]. All non-hydrogen atoms were refined with anisotropic displacement parameters and all hydrogen atoms were placed in idealized positions, which were refined as rigid atoms with the relative isotropic displacement parameters. CIF and checkCIF files for X-ray diffraction data of $\mathbf{1} \supset$ DMPhen are available in Supplementary Materials.

\section{Results and Discussion}

As shown in Scheme 2, we previously demonstrated by ${ }^{1} \mathrm{H}$ NMR spectral changes and ${ }^{1} \mathrm{H}$ NMR spectroscopic titration experiments that macrocycle $\mathbf{1}$ very strongly binds 2,9-dimethyl-1,10-phenanthroline (DMPhen) [22]. We expected that the corresponding [2]pseudorotaxane structures would be formed by stabilization from the cooperative effects of NH-N hydrogen bonding between the isophthalamide protons and the DMPhen nitrogen atoms, as well as by $\pi$-stacking of the two $\pi$-electron-rich aromatic rings of macrocycle 1 with the $\pi$-electron-deficient aromatic ring of the neutral phenanthroline derivative in $\mathrm{CDCl}_{3}$.

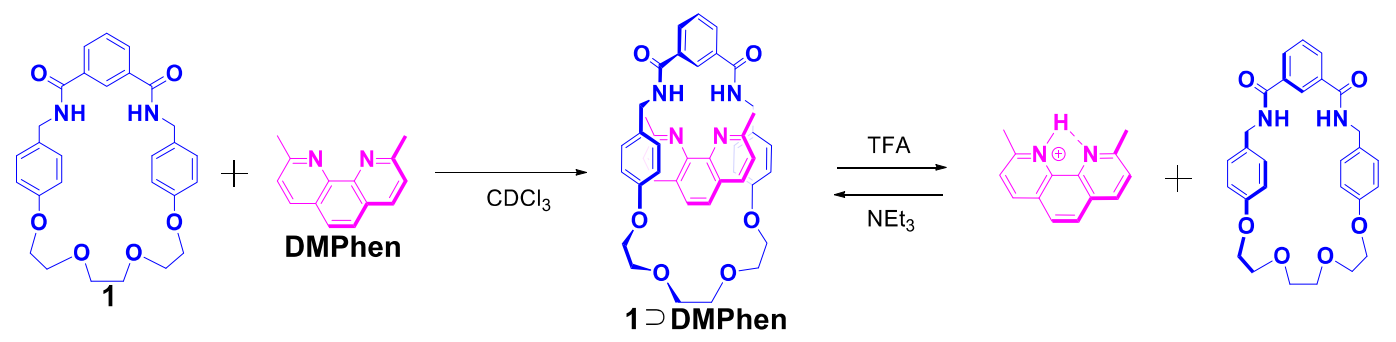

Scheme 2. Formation of a pseudorotaxane ( $1 \supset$ DMPhen) and an acid-base threading-dethreading reaction.

In order to define the structure of the [2]pseudorotaxane in the solid state, single crystals of $1 \supset$ DMPhen suitable for X-ray diffraction analysis were grown by slow evaporation of a dioxane solution of the [2]pseudorotaxane [27]. The X-ray diffraction analysis revealed a [2]pseudorotaxane-like molecular geometry for $\mathbf{1} \supset$ DMPhen in the solid state (Figure 1). The phenanthroline unit of DMPhen orthogonally aligns with the isophthalamide moiety of the macrocycle $\mathbf{1}$ and penetrates in the macrocycle 1. As is shown in Figure 1c in more detail, DMPhen is disproportionally located in one side of the macrocycle aperture. Benzene rings of the macrocycle (I and II) are located on and $\pi$-stacked with six-membered rings of the DMPhen labeled with A and B, respectively, whereas ring C of the DMPhen is out of the macrocycle. Interplanar angles and the approximate distance between benzene ring I and phenanthroline are $12.3^{\circ}$ and $3.18-3.72 \AA$, respectively, and those corresponding to ring II and phenanthroline are $3.5^{\circ}$ and $3.30-3.46 \AA$, respectively. The phenanthroline nitrogen atoms (N3 and N4) are coordinated via hydrogen bonding with the isophthalamide and the aromatic protons. The related

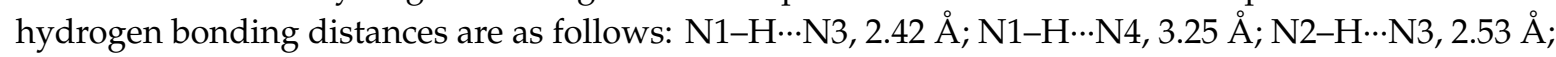

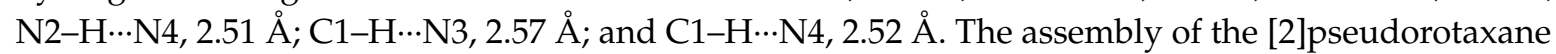
is further stabilized by weak hydrogen bonds, that is, a $\mathrm{CH} / \pi$ interaction between the methyl group of DMPhen and the benzene ring of $\mathbf{1}(\mathrm{C} 42-\mathrm{H} \cdots \mathrm{C} 1$ with $2.79 \AA)$ and a $\mathrm{CH} / \mathrm{O}$ interaction between the phenanthroline aromatic and the polyether chain of the macrocycle $(\mathrm{C} 38-\mathrm{H} \cdots \mathrm{O} 1$ with a distance of $2.59 \AA)$. 
(a)

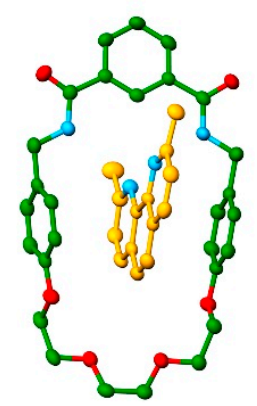

(b)

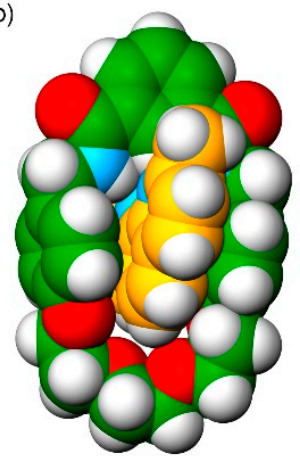

(c)

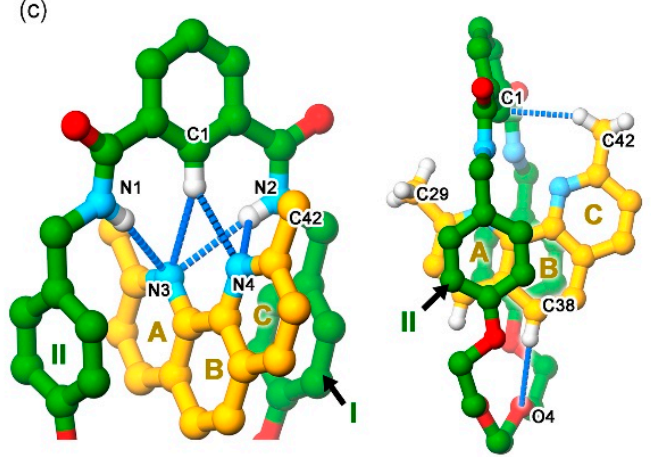

Figure 1. Crystal structure of pseudorotaxane $1 \supset$ DMPhen: (a) anisotropic displacement plot with $50 \%$ probability ellipsoids, where hydrogen atoms are omitted for clarity; (b) space-fill model; (c) intermolecular interactions between $\mathbf{1}$ and DMPhen, where only selected hydrogen atoms relating to the interactions are shown. Color code: C (green or yellow), O (red), N (cyan), H (white). Intermolecular interactions are described with blue dotted lines.

In order to obtain a rotaxane structure using macrocycle $\mathbf{1}$ with an axle component containing a phenanthroline moiety, we used phenanthroline derivative 2 , which contains a para-substituted benzaldehyde group as a reactive group at the 2- and 9-positions on the phenanthroline ring. Upon addition of phenanthroline derivative $\mathbf{2}$ to a solution of the macrocycle $\mathbf{1}$ in $d$-chloroform, the ${ }^{1} \mathrm{H}$ NMR spectra revealed significant downfield shifts for the macrocyclic amide (d) and the isophthalic aromatic protons $(\mathrm{a}, \mathrm{b}$, and $\mathrm{c})$, which indicate that hydrogen bonding is formed between the amide hydrogens of macrocycle 1 and the nitrogen atoms of phenanthroline derivative $\mathbf{2}$ (Figure 2). In addition, the upfield shifts of the signals of the benzylic phenyl protons ( $\mathrm{f}$ and $\mathrm{g}$ ) of $\mathbf{1}$ imply the existence of interactions between the electronically complementary aromatic rings of $\mathbf{1}$ and $\mathbf{2}$. The ${ }^{1} \mathrm{H}$ NMR spectrum of an equimolar mixture $(19 \mathrm{mM})$ of $\mathbf{1}$ and $\mathbf{2}$ in $\mathrm{CDCl}_{3}$ corroborates the formation of pseudorotaxane $1 \supset$ 2. The association constants $(\mathrm{Ka})$ for the complexation were measured by ${ }^{1} \mathrm{H}$ NMR titration experiments [28]. Monitoring the downfield shift of protons $\mathrm{c}$ and $\mathrm{d}$ and the upfield shift of protons $\mathrm{f}$ and $g$ upon adding 2 allowed us to estimate an association constant of $3.5 \pm 0.4 \times 10^{3}$. It should be noted that the increase in the binding affinity of the macrocycle toward 2 is by a factor of approximately 8 and 1.5 higher relative to those of unsubstituted phenanthroline and 2,9-dimethylphenanthroline, respectively [22].

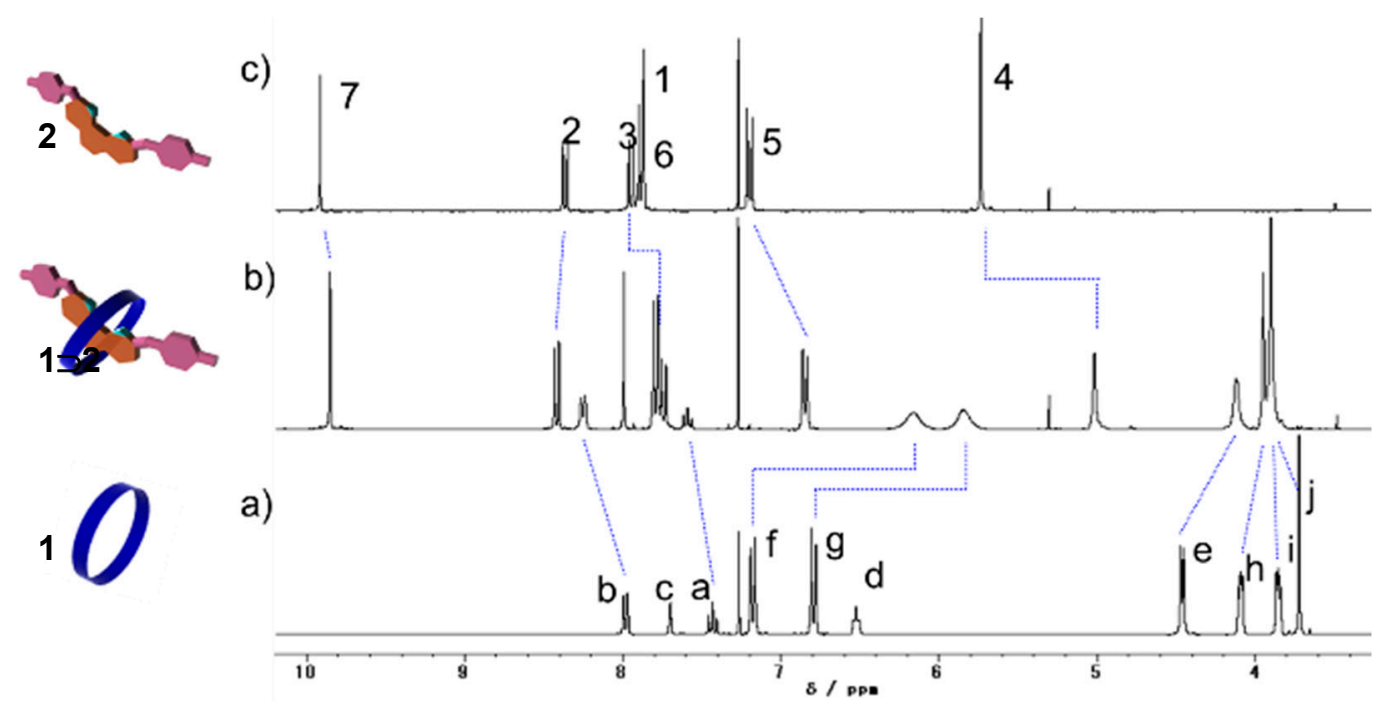

Figure 2. Partial ${ }^{1} \mathrm{H}$ NMR spectra $\left(300 \mathrm{MHz}, \mathrm{CDCl}_{3}, 3.2-10.2 \mathrm{ppm}\right)$ of (a) macrocycle 1, (b) pseudorotaxane $\mathbf{1} \supset \mathbf{2}$, and (c) axle 2. 
The new rotaxane 3 was obtained from the reaction of isophthalamide-containing macrocycle 1 with the phenanthroline bis-aldehyde 2 in $\mathrm{CDCl}_{3}$, followed by a treatment with tritylaniline (stopper), $\mathrm{MgSO}_{4}$ (dehydrating agent), and $\mathrm{NaBH}(\mathrm{OAc})_{3}$ (reducing agent) (Scheme 3) $[18,29,30]$. Pure [2]rotaxane 3 and its corresponding free dumbbell 4 were isolated by preparative GPC in $60 \%$ and $15 \%$ yield, respectively. During the rotaxane synthesis, the free dumbbell 4 was isolated probably due to the dissociation of the axle component 2 from the macrocycle 1 during two-step reactions of reductive amination.
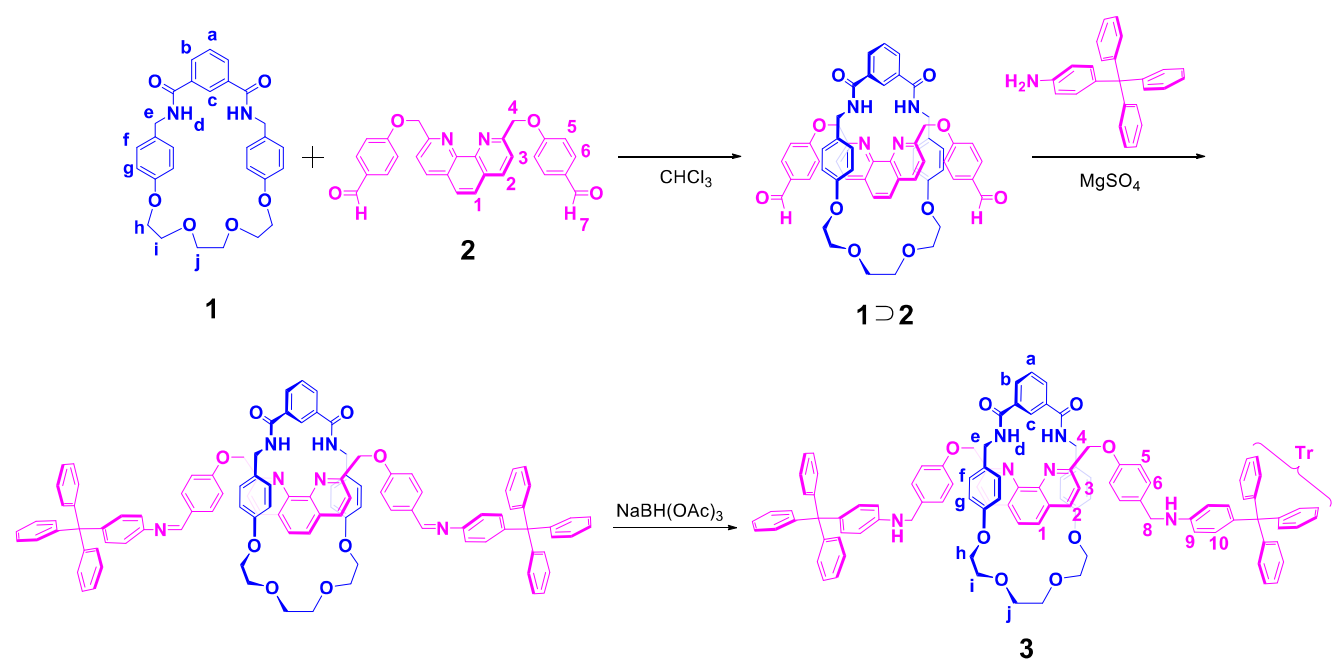

Scheme 3. Synthetic scheme of [2]rotaxane 3 via reductive amination.

The ${ }^{1} \mathrm{H}$ NMR experiments were performed in $\mathrm{CDCl}_{3}$ in order to confirm the formation of [2]rotaxane 3. As shown in Figure 3, the spectrum of [2]rotaxane 3, along with those of the constituent components (i.e., dumbbell 4 and macrocycle 1) confirmed the interlocked structure and show that, under neutral conditions, macrocycle $\mathbf{1}$ in [2]rotaxane $\mathbf{3}$ is largely localized on the phenanthroline moiety of the dumbbell.

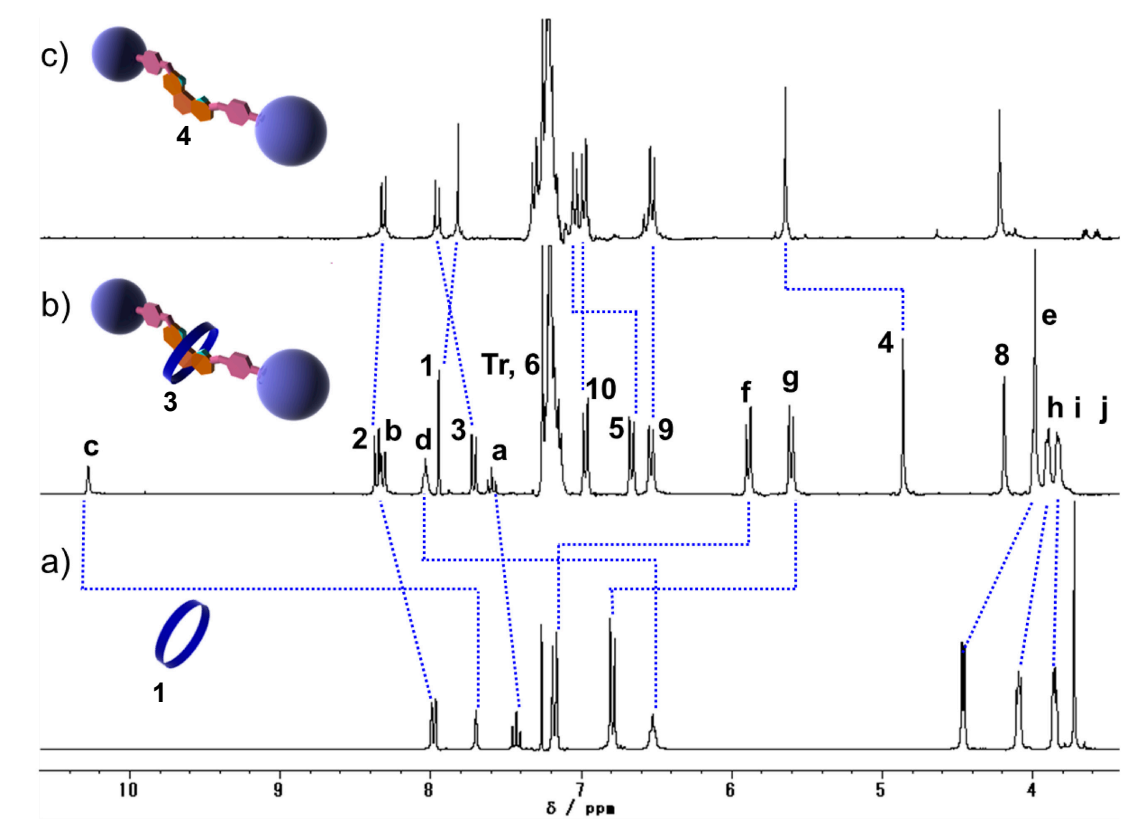

Figure 3. Partial ${ }^{1} \mathrm{H}$ NMR spectra (300 MHz, $\left.\mathrm{CDCl}_{3}, 3.4-10.6 \mathrm{ppm}\right)$ of (a) macrocycle 1, (b) rotaxane 3, and (c) axle 4 . 
In order to demonstrate that [2]rotaxane 3 represents a $\mathrm{pH}$-controllable rotaxane-based molecular switch, an excess of trifluoroacetic acid (TFA) was added to a solution of 3 in $\mathrm{CDCl}_{3}$. The ${ }^{1} \mathrm{H} \mathrm{NMR}$ spectrum of the resulting mixture (Figure $4 a, b$ ) revealed that the protonation of the phenanthroline gives rise to a migration of macrocycle 1 to the protonated aniline site. This interpretation was supported by significant changes of the chemical shifts corresponding to the isophthalic aromatic protons $(a, b$, and c), which return almost to the values of uncomplexed macrocycle 1, due to the dissociation of the hydrogen bonding between the isophthalic amide and the phenanthroline, and by the downfield shifts of the signals for the benzylic phenyl protons ( $f$, having a larger shift and $g$, a smaller shift) of macrocycle 1 due to the removal from the phenanthroline site and the fact of staying at one of the oxyphenylene rings in the axle component via $\pi$-stacking (Figure $4 \mathrm{~b}$ ). Moreover, the signals for protons $\mathrm{H}_{4}$ and $\mathrm{H}_{\mathrm{e}}$ were shifted downfield due to the removal of macrocycle 1 from the phenathroline site. In addition, the polyether protons (h, i, and j) are slightly upfield shifted and broadened, which results in hydrogen bonding interactions between the ether oxygen atoms and the ammonium hydrogen atoms [31,32]. The results thus indicate that macrocycle $\mathbf{1}$ moves to both of the oxyphenylene sites and the protonated aniline sites on either side upon the addition of acid. On the other hand, upon the addition of an excess of triethylamine $\left(\mathrm{Et}_{3} \mathrm{~N}\right)$ to [2] rotaxane 3 under the acidic condition in $\mathrm{CDCl}_{3}$, the protonated groups of the anilines and the phenanthroline are neutralized and the hydrogen bonds between the polyether moiety and the ammonium groups are cleaved. Furthermore, the formation of hydrogen bonds between the amide hydrogen atoms of macrocycle $\mathbf{1}$ and the phenanthroline nitrogen atoms of the dumbbell was confirmed by the identical ${ }^{1} \mathrm{H}$ NMR spectra for [2]rotaxane 3 under neutral and basic conditions.

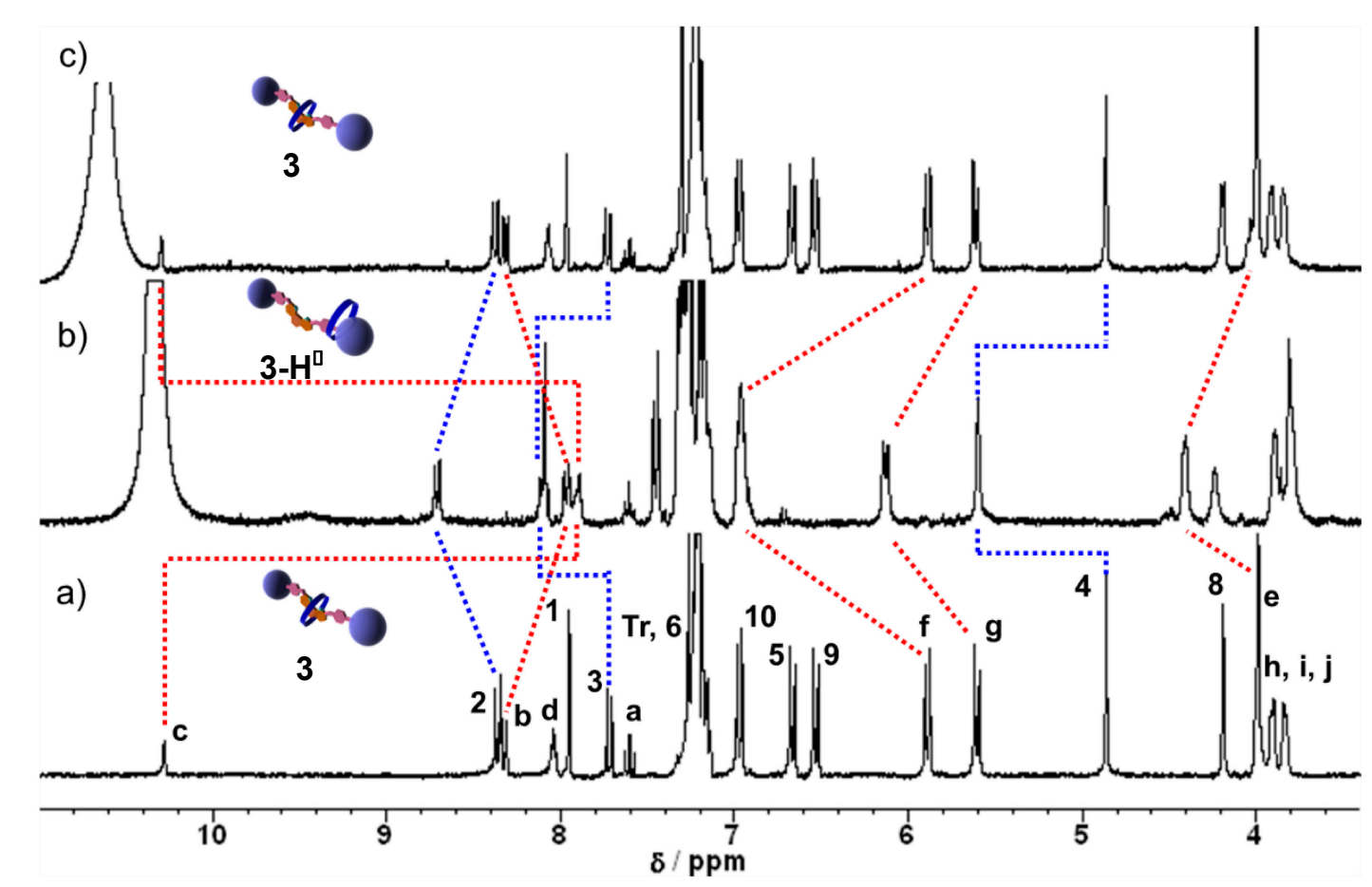

Figure 4. Partial ${ }^{1} \mathrm{H}$ NMR spectra (300 MHz, $\mathrm{CDCl}_{3}, 3.4-11.0 \mathrm{ppm}$ ) of (a) rotaxane 3 , (b) rotaxane $3-\mathrm{H}^{+}$ obtained after adding excess TFA to rotaxane 3 , and (c) rotaxane 3 obtained after adding excess $\mathrm{Et}_{3} \mathrm{~N}$ to rotaxane $3-\mathbf{H}^{+}$.

\section{Conclusions}

In conclusion, we successfully demonstrated that phenanthroline-containing symmetric [2]rotaxane 3 can serve as a $\mathrm{pH}$-controllable reversible molecular switch. 3 is synthesized without a template via interpenetration by hydrogen bonding and $\pi$-interaction, which provides a simple synthetic route to $\mathrm{pH}$-responsive molecular switches that do not require additional procedures such as removal 
of metal templates. Should 3 be applied in molecular sensors and molecular devices in the future, contamination-free materials could potentially be obtained for molecular machines. The synthesis of the corresponding asymmetric template-free chiral [2]rotaxanes that contain a phenanthroline moiety and the investigation of their molecular sensors and molecular shuttling properties are currently in progress.

Supplementary Materials: The following are available online at http:/www.mdpi.com/2073-8994/11/9/1137/s1: CIF and checkCIF files for X-ray diffraction data of $\mathbf{1} \supset$ DMPhen.

Author Contributions: M.M. (Masahiro Muraoka) conceived and designed the experiments; K.A., S.F., and R.Y. performed the experiments and analyzed the data; I.H. performed the X-ray diffraction analysis; M.M. (Mikiji Miyata), M.M. (Michihisa Murata), and Y.N. contributed scientific guidance; M.M. (Masahiro Muraoka), I.H., K.A., and R.Y. wrote the paper.

Funding: This research received no external funding.

Conflicts of Interest: The authors declare no conflict of interest. The funding sponsors had no role in the design of the study; in the collection, analyses, or interpretation of data; in the writing of the manuscript; and in the decision to publish the results.

\section{Appendix A. General}

${ }^{1} \mathrm{H}$ NMR and ${ }^{13} \mathrm{C}$ NMR spectra of [2]rotaxane 3 and dumbbell 4 as well as ROESY NMR spectra of [2]rotaxane 3 are filed here. Details of each chart are mentioned in Materials and Methods.

\section{Appendix B. ${ }^{1} \mathrm{H}$ and ${ }^{13} \mathrm{C}$ NMR Spectra of [2]Rotaxane 3}

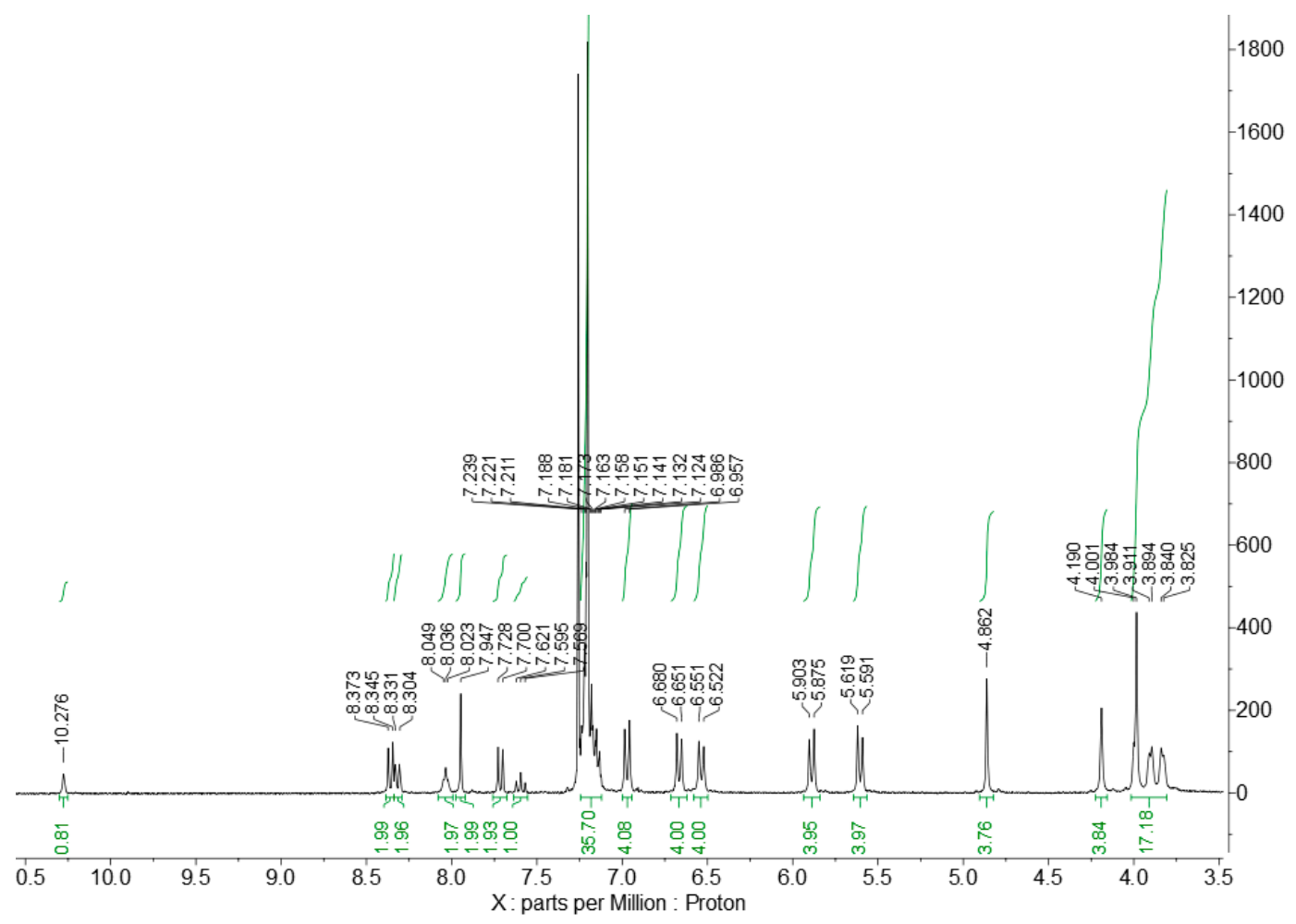

(a) ${ }^{1} \mathrm{H}$ NMR spectrum (300 $\mathrm{MHz}, \mathrm{CDCl}_{3}, 3.5-10.5 \mathrm{ppm}$ ) of [2]rotaxane 3.

Figure A1. Cont. 


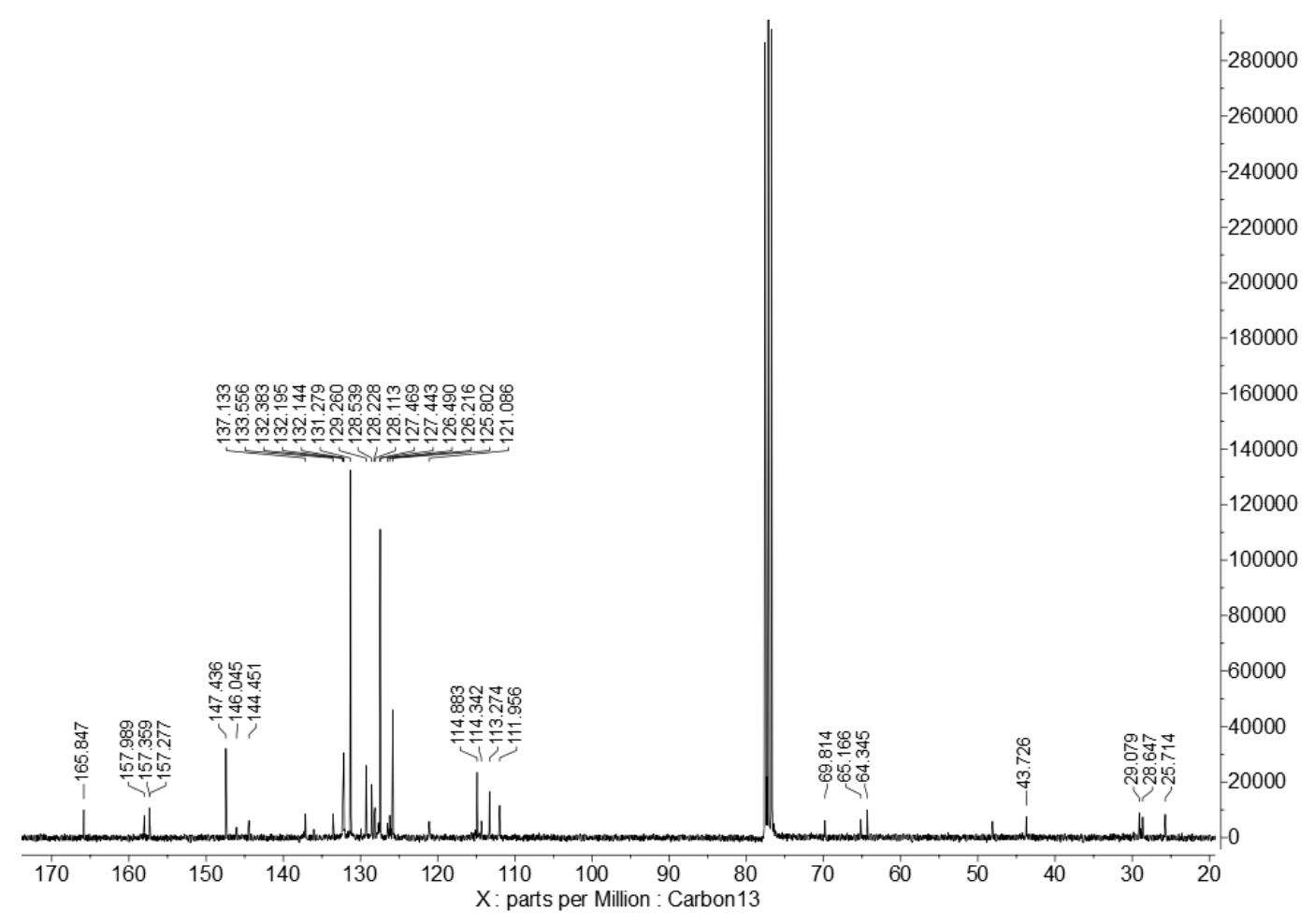

(b) ${ }^{13} \mathrm{C}$ NMR spectrum (300 MHz, $\mathrm{CDCl}_{3}, 20-175 \mathrm{ppm}$ ) of [2]rotaxane 3

Figure A1. ${ }^{1} \mathrm{H}$ and ${ }^{13} \mathrm{C}$ NMR Spectra of [2]Rotaxane 3.

\section{Appendix C. ROESY NMR Spectra of [2]Rotaxane 3}

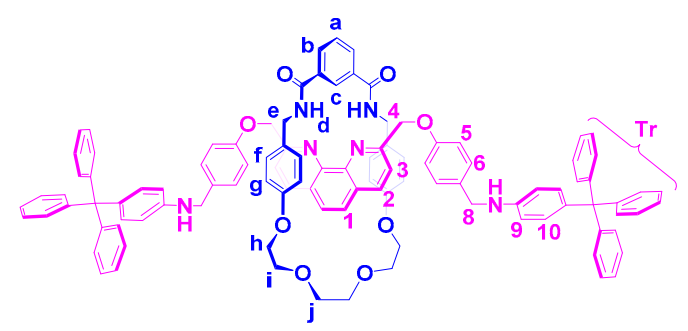

(a) Molecular structure of [2]rotaxane 3.

Figure A2. Cont. 


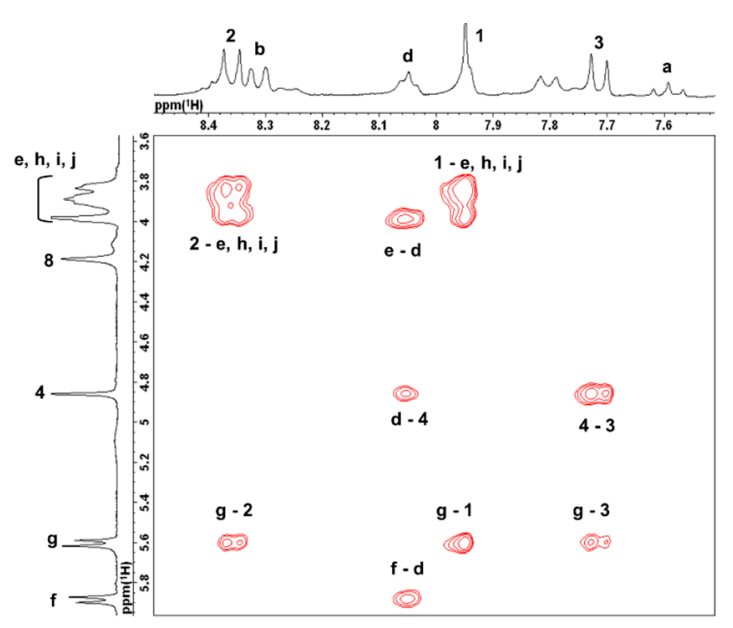

(b) ROESY NMR Spectrum (300 MHz, $\mathrm{CDCl}_{3}$, between 7.5-8.5 ppm and 3.6-6.0 ppm) of [2]Rotaxane 3.

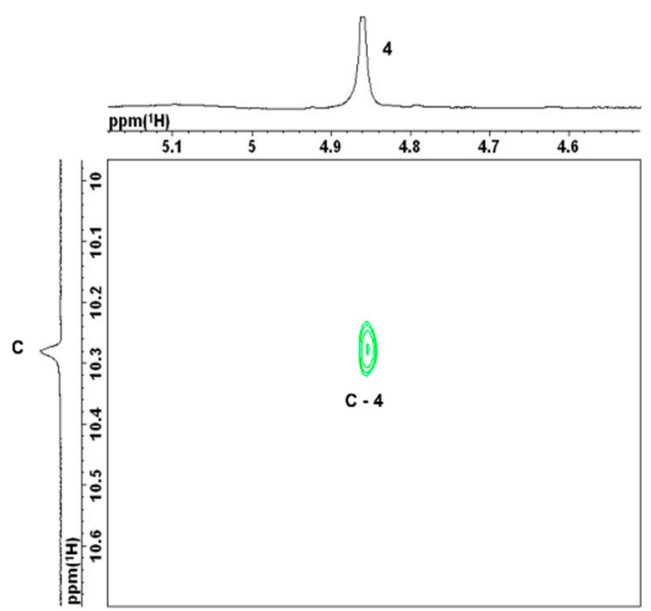

(c) ROESY NMR Spectrum (300 MHz, $\mathrm{CDCl}_{3}$, between $4.5-5.2 \mathrm{ppm}$ and 10.0-10.7 ppm) of [2]Rotaxane 3.

Figure A2. ROESY NMR Spectra of [2]Rotaxane 3.

\section{Appendix D. ${ }^{1} \mathrm{H}$ and ${ }^{13} \mathrm{C}$ NMR Spectra of Dumbbell 4}

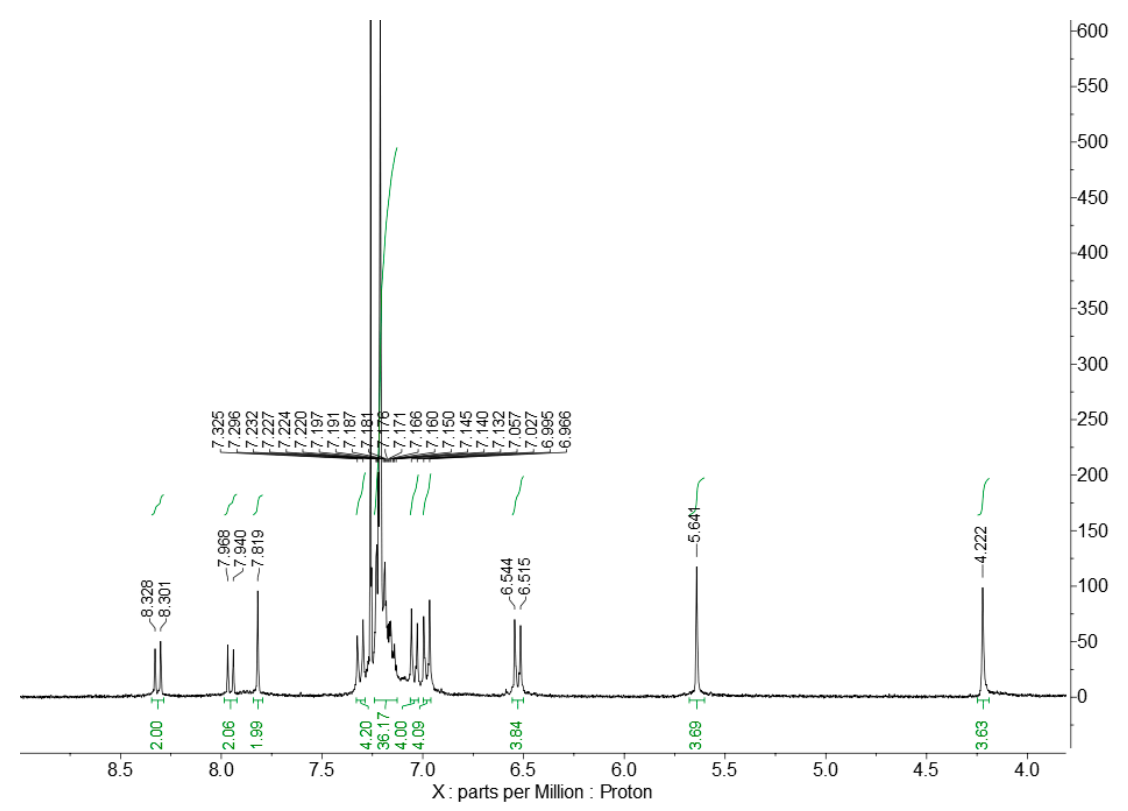

(a) ${ }^{1} \mathrm{H}$ NMR spectrum (300 MHz, $\left.\mathrm{CDCl}_{3}, 3.8-9.0 \mathrm{ppm}\right)$ of dumbbell 4.

Figure A3. Cont. 


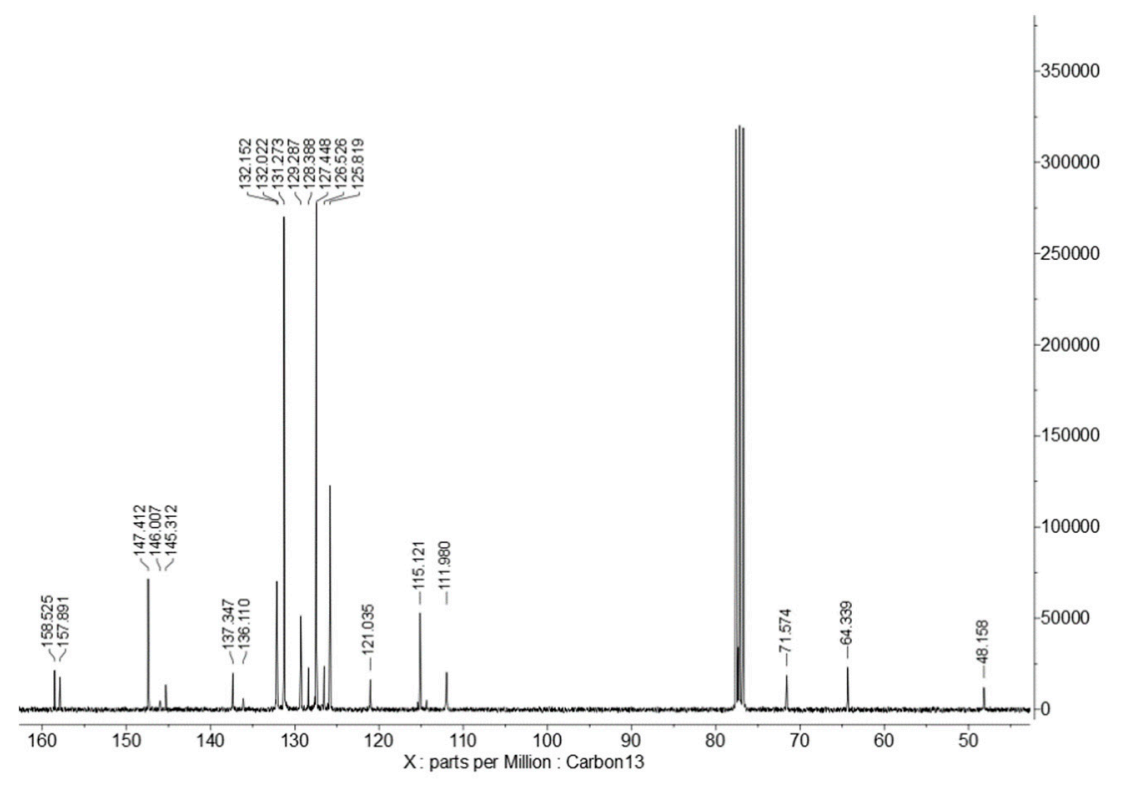

(b) ${ }^{13} \mathrm{C}$ NMR spectrum (300 MHz, $\left.\mathrm{CDCl}_{3}, 42-162 \mathrm{ppm}\right)$ of dumbbell 4.

Figure A3. ${ }^{1} \mathrm{H}$ and ${ }^{13} \mathrm{C}$ NMR Spectra of Dumbbell 4.

\section{References}

1. Erbas-Cakmak, S.; Leigh, D.A.; McTernan, C.T.; Nussbaumer, A.L. Artificial Molecular Machines. Chem. Rev. 2015, 115, 10081-10206. [CrossRef] [PubMed]

2. Xue, M.; Yang, Y.; Chi, X.; Yan, X.; Huang, F. Development of Pseudorotaxanes and Rotaxanes: From Synthesis to Stimuli-Responsive Motions to Applications. Chem. Rev. 2015, 115, 7398-7501. [CrossRef] [PubMed]

3. van Dongen, S.F.M.; Cantekin, S.; Elemans, J.A.A.W.; Rowan, A.E.; Nolte, R.J.M. Functional interlocked systems. Chem. Soc. Rev. 2014, 43, 99-122. [CrossRef] [PubMed]

4. Beves, J.E.; Blight, B.A.; Campbell, C.J.; Leigh, D.A.; McBurney, R.T. Strategies and Tactics for the Metal-Directed Synthesis of Rotaxanes, Knots, Catenanes, and Higher Order Links. Angew. Chem. Int. Ed. 2011, 50, 9260-9327. [CrossRef] [PubMed]

5. Stodddart, J.F. Mechanically Interlocked Molecules (MIMs)—Molecular Shuttles, Switches, and Machines

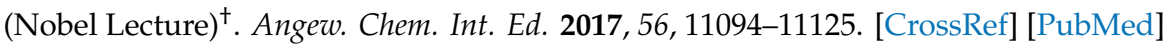

6. Sauvage, J.P. From Chemical Topology to Molecular Machines (Nobel Lecture) ${ }^{\dagger}$. Angew. Chem. Int. Ed. 2017, 56, 11080-11093. [CrossRef] [PubMed]

7. Lewis, J.E.M.; Galli, M.; Goldup, S.M. Properties and emerging applications of mechanically interlocked ligands. Chem. Commun. 2017, 53, 298-312. [CrossRef]

8. Langton, M.J.; Beer, P.D. Rotaxane and catenane host structures for sensing charged guest species. Acc. Chem. Res. 2014, 47, 1935-1949. [CrossRef]

9. Neal, E.A.; Goldup, S.M. Chemical consequences of mechanical bonding in catenanes and rotaxanes: isomerism, modification, catalysis and molecular machines for synthesis. Chem. Commun. 2014, 50, 5128-5142. [CrossRef]

10. Muraoka, M.; Ohta, M.; Mizutani, Y.; Takezawa, M.; Matsumoto, A.; Nakatsuji, Y. Formation of a pseudorotaxane, capable of sensing cations via dethreading molecular motion, from a cryptand and bipyridinium salts. J. Incl. Phenom. Macrocycl. Chem. 2014, 78, 137-144. [CrossRef]

11. Nakazono, K.; Kuwata, S.; Takata, T. Crown Ether-tert-Ammonium Salt Complex Fixed as Rotaxane and Its Derivation to Nonionic Rotaxane. Tetrahedron Lett. 2008, 49, 2397-2401. [CrossRef]

12. Suzuki, S.; Nakazono, K.; Takata, T. Selective transformation of a crown ether/sec-ammonium salt-type rotaxane to $\mathrm{N}$-alkylated rotaxanes. Org. Lett. 2010, 12, 712-715. [CrossRef] [PubMed] 
13. Chmielewski, M.J.; Davis, J.J.; Beer, P.D. Interlocked host rotaxane and catenane structures for sensing charged guest species via optical and electrochemical methodologies. Org. Biomol. Chem. 2009, 7, 415-424. [CrossRef] [PubMed]

14. Thomas, S.W., III; Joly, G.D.; Swager, T.M. Chemical sensors based on amplifying fluorescent conjugated polymers. Chem. Rev. 2007, 107, 1339-1386. [CrossRef] [PubMed]

15. McQuade, D.T.; Pullen, A.E.; Swager, T.M. Conjugated Polymer-Based Chemical Sensors. Chem. Rev. 2000, 100, 2537-2574. [CrossRef] [PubMed]

16. Ma, X.; Tian, H. Bright functional rotaxanes. Chem. Soc. Rev. 2010, 39, 70-80. [CrossRef]

17. Wenz, G.; Han, B.-H.; Müller, A. Cyclodextrin rotaxanes and polyrotaxanes. Chem. Rev. 2006, 106, $782-817$. [CrossRef]

18. Leigh, D.A.; Thomson, A.R. Switchable dual binding mode molecular shuttle. Org. Lett. 2006, 8, 5377-5379. [CrossRef]

19. Vidonne, A.; Philp, D. Integrating replication processes with mechanically interlocked molecular architectures. Tetrahedron 2008, 64, 8464-8475. [CrossRef]

20. Kosikova, T.; Hassan, N.I.; Cordes, D.B.; Slawin, A.M.Z.; Philp, D. Orthogonal recognition processes drive the assembly and replication of a [2]Rotaxane. J. Am. Chem. Soc. 2015, 137, 16074-16083. [CrossRef]

21. Fletcher, B.E.; Peach, M.J.G.; Evans, N.H. Rapidly accessible "click" rotaxanes utilizing a single amide hydrogen bond templating motif. Org. Biomol. Chem. 2017, 15, 2797-2803. [CrossRef] [PubMed]

22. Muraoka, M.; Irie, H.; Nakatsuji, Y. Acid/base controllable molecular switch based on a neutral phenanthroline guest penetrated pseudorotaxane. Org. Biomol. Chem. 2010, 8, 2408-2413. [CrossRef] [PubMed]

23. Wang, K.; Yee, C.C.; Au-Yeung, H.Y. Facile syntheses of [3]-, [4]- and [6] catenanes templated by orthogonal supramolecular interactions. Chem. Sci. 2016, 7, 2787-2792. [CrossRef] [PubMed]

24. Sheldrick, G.M. SHELXT-integrated space-group and crystal-structure determination. Acta Crystallogr. Sect. A 2015, 71, 3-8. [CrossRef] [PubMed]

25. Rigaku. CrystalStructure. Ver. 4.2; Rigaku Corporation: Tokyo, Japan, 2015.

26. Sheldrick, G.M. Crystal structure refinement with SHELXL. Acta Crystallogr. Sect. C 2015, 71, 3-8. [CrossRef] [PubMed]

27. The Cambridge Crystallographic Data Centre. Crystal data of [2] pseudorotaxane 1כDMPhen: $\left(\mathrm{C}_{28} \mathrm{H}_{30} \mathrm{~N}_{2} \mathrm{O}_{6}\right) \bullet\left(\mathrm{C}_{14} \mathrm{H}_{12} \mathrm{~N}_{2}\right) \bullet 0.5\left(\mathrm{C}_{4} \mathrm{H}_{8} \mathrm{O}_{2}\right) \bullet \mathrm{H}_{2} \mathrm{O}, \mathrm{FW}=760.89, a=8.83401(16) \AA, b=12.5026(2) \AA, c=18.7047(3)$ $\AA, \alpha=103.5820(9)^{\circ}, \beta=94.5117(9)^{\circ}, \gamma=103.4930(9)^{\circ}, V=1933.14(6) \AA^{3}, T=153 \mathrm{~K}$, triclinic, space group $P-1$, $\mathrm{Z}=2,13886$ collected, 6848 unique $\left(R_{\text {int }}=0.0536\right)$ reflections, the final $R 1$ and $w R 2$ values $0.0504(\mathrm{I}>2.0 \sigma(\mathrm{I}))$ and 0.1459 (all data), respectively. (CCDC-1947111) contain the supplementary crystallographic data for this paper. Available online: www.ccdc.cam.ac.uk/ (accessed on 14 August 2019).

28. Hirose, K. A Practical Guide for the Determination of Binding Constants. J. Incl. Phenom. Macrocycl. Chem. 2001, 39, 193-209. [CrossRef]

29. Cantrill, S.J.; Rowan, S.J.; Stoddart, J.F. Rotaxane formation under thermodynamic control. Org. Lett. 1999, 1, 1363-1366. [CrossRef]

30. Rowan, S.J.; Stoddart, J.F. Thermodynamic synthesis of rotaxanes by imine exchange. Org. Lett. 1999, 1, 1913-1916. [CrossRef]

31. De Bo, G.; Dolphijn, G.; McTernan, C.T.; Leigh, D.A. [2]Rotaxane Formation by Transition State Stabilization. J. Am. Chem. Soc. 2017, 139, 8455-8457. [CrossRef]

32. Zheng, H.; Zhou, W.; Lv, J.; Yin, X.; Li, Y.J.; Liu, H.; Li, Y.L. A Dual-Response [2] Rotaxane Based on a 1,2,3-Triazole Ring as a Novel Recognition Station. Chem. Eur. J. 2009, 15, 13253-13262. [CrossRef]

(C) 2019 by the authors. Licensee MDPI, Basel, Switzerland. This article is an open access article distributed under the terms and conditions of the Creative Commons Attribution (CC BY) license (http://creativecommons.org/licenses/by/4.0/). 